\title{
Research on Material Design of Decoration Art Glass
}

\author{
Yuanyuan $\mathrm{He}^{1, \mathrm{a}}$ \\ ${ }^{1}$ School of Art \& Design, Wuhan Textile University, Wuhan 430074, China; \\ ahyyedu@163.com
}

Keywords: Glass, Decoration Art, Beauty of Material.

\begin{abstract}
Glass material enjoys light transmission, plasticity and polychroism which can not be found in other materials. By virtue of such distinctive characters, artworks and practical daily necessities made up of glass materials are emerging in an endless stream. In addition, it constantly beautifies the living environment of modern people through different forms of artistic expression.
\end{abstract}

\section{Introduction}

Light Transmission, as one of the main characteristics of glass, is full of the charm and luster. In addition, color can enrich the artistic effect of glass and makes people feel happy and relaxed, and plasticity character of glass is an important way to shape artistic beauty. On the other hand, the variability of glass texture becomes the biggest difference with other materials. Other materials such as wood, metal, fiber etc, are relatively stable in aspect of texture. While texture of glass can be described at will in accordance with mixture ratio of raw material and process planning.

\section{The Characteristics of Decoration Art Glass}

Light Transmission. At present, with evolution and development of material formulas, the light transmittance of glass has been improved correspondingly. Light Transmission of glass can be divided into non-transparent, fully transparent and semi-transparent in accordance with demands of use and different decorative effect.

Non-transparent glass always gives viewers illusion of material. Some looks like a jade, some looks like metal and some looks like chinaware.Oiva Toikka, an artist, has been engaged in research of ceramic arts for as long as 6 years. Then he puts his experience of creation into glass art. The glass sculpture based on the "bird"theme is classic work of his creation. The sculpture adopts artistic language of ceramics, with smooth surface,pure color. And its appearance also presents concise, honest and simple as well as plump characteristic. The work fully expresses author's attachment and affection to the Nature.

Fully transparent glass usually provide designers greater space for creation. Therefore, glass of high transparency is widely used in various glassware,glass furniture and ornaments. The texture of material also increases sense of fashion for our modern life, which is particularly popular in the contemporary young generation. The gleaming and colorful fully transparent glass decoration provides people with glittering and translucent visual perception.Most glassware is designed with full transparency so as to set off the color and lustre or texture of the object.(picture 3-1)

Color Decoration. Multi-color of glass material can usually be realized through technological process. It can also form a variety of colors through putting various oxides and colorants in glass raw materials.

A variety of chemical compositions and elements in glass can exert different influences on formulation of color. A same kind of color can be achieved through combination of different material elements. Even slight changes in material composition will produce different color effects, which provides more opportunities and space for glass art creation.

The color, like a coat, changes colorless and transparent image of glass in the heart of people. Different colors can give glasswork different artistic temperaments. The western designers take multi-color of glass as the symbol of creation, which not only enhances the artistic expressiveness of 
works but also can stimulate the inner sensation of appreciators. For instance, Harvey Littleton,the father of glass art in United States, is good at regarding color as his creation language. His works are extremely simple and concise in form, basically completed through way of cutting and restructuring. However, abundant color levels and succinct lines form a sharp contrast. The color designed by him sometimes adopts gradual change in color and sometimes through transition among hues. The multiple colors will produce a subtle interaction under action of glass transparency.(Fig 1)

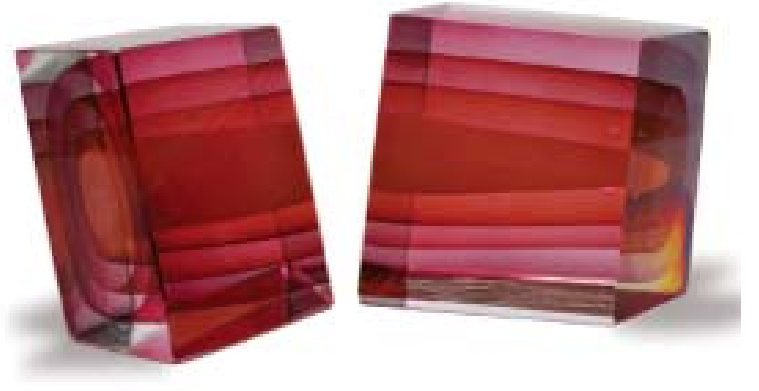

Fig. 1 (America) Harvey Littleton: Parallelogram

The glass material will form various colors in accordance with different material technologies and abundant colors are able to bring pleasure and joy to people. No matter for glass arts of diverse forms, glass furniture or utensils, the vitality and affinity of design can be enhanced through multiple colors. Modeling Free. The existence state of glass is mainly determined by temperature. Under different temperature nodes, glass will present different viscosities. Under normal circumstance, there is inverse proportion relationship between firing temperature of glass and its viscosity.In actual operation process, when the firing temperature reaches $800^{\circ} \mathrm{C}$, glass will be gradually converted into liquid. Therefore, designers and artists always debug different temperatures in their creation process to observe the different forms of glass that may appear, such as degree of bending, melting state, and angle of depression etc. In production, some unexpected shapes of glass are always caused by flexibility of glass. Sodium carbonate and potassium carbonate in production of glass can reduce the melting point of glass so as to transform the hard substance into soft one.

The creator can choose the appropriate fusion point to create the desired modeling effects in accordance with demand of creation. In life, glass arts of different shapes and glassware, glass curtain wall on surface of buildings, as well as curve glass furniture interpret the plasticity of glass in best way. Therefore, on basis of such character of glass, glass artists in eastern and western countries have developed various process methods such as hot melting, hot bending, casting, lamp working, and blowing etc. All of these methods soften and shape the glass through high temperature and corresponding tools.

"Fabric vase" , the work of Fulvio Bianconi, which makes the hard glass material in traditional understanding into silky soft vase. The surface of vase is decorated with texture of fabric. The overall shape is as soft and graceful as skirts. Various glassworks of Venini make good interpretation of plasticity character of glass(Fig. 2). Designers are able to obtain a variety of creative inspiration from it, on basis of which, it constantly brings a variety of innovation and surprise to a large number of audience.

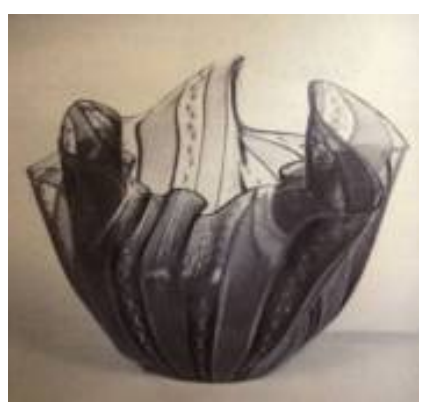

Fig. 2 (Italy) Niko: Fabric Vase 
As it were, plasticity character of glass is an important way to shape artistic beauty. It changes people's previous understanding of sharp and forbidding image of glass and replaces it with a kind of curve modeling language with more affinity.

\section{The Texture of Decoration Art Glass}

The word "texture" emphasizes the feeling brought by quality, material, skin texture and other characters of substance. Different materials will bring different feelings to people. In material arts, the western artists always make use of inherent characteristic of material to express some kind of subjective feeling. Therefore, texture may not always be a presentation of objective truth, it is results of people's subjective feelings. Glass material provide a broad creation space for creators , which is the main reason for glass to maintain its vitality after passing through the ancient and modern times. Transparent Glass.Fully transparent crystal glass always brings the texture feeling of as translucent as diamond to people. Compared with ordinary transparent glass, it enjoys higher refractive index and material accuracy. Plus the ingenious cutting technology of designers, the glass will be more shining and dazzling. Crystal glass has a long history of development in the world. It is first developed by British in seventeenth Century. The birth of crystal glass provides space for development of a variety of glass ornaments and accessories. The value of material itself is thus doubled. In life, crystal glass becomes the common product used to imitate diamond. Therefore, such glass enjoys broad development space and good potential in market. After processing the glass of higher refractive index through ingenious technology by creators, the glass can shine brightly like diamond.

Glass material always gives us a clear and bright impression. In fact, designers can make the original transparent material become porcelain-like through changing the proportioning method of material composition. As mentioned before, texture of glass-imitated porcelain can be achieved through opacification. In practical creation process, designers will prepare formulations in accordance with personal demands of creation.

Gentle Glass. The texture of early glass is totally different with the present crystal and transparent glass. Material formula of the early Chinese lead -based glass and potassium- based glass brings glass a kind of compatible and plaintemperament. Therefore, glass are often used by the ancients to imitate a variety of jadeware or porcelain. Especially in Chinese Spring and Autumn Period, Xi Han Dynasty and Dong Han Dynasty, as texture of glass is closely similar to that of jade, it is often made into Glass Jade, glass earring and glass garment etc. Then, until the emergence of decolorization materials and technology, glass starts to present its colorless and transparent state. Therefore, regarding "glittering and translucent" as the only state of glass material is bound to be a misunderstanding and one-sidedness.

There is an inevitable connection between the thick texture of glass and its material composition, some of which are results of such foreign substances as Fe2O3,TiO2,V2O5,CuO, CoO, NiO etc contained in glass composition; and some of which are because there is un-melted particles or opalizer in glass composition. And some are affected by the content of silicon dioxide in glass composition. When the content of silicon dioxide is small, the light transmittance of glass will become lower. In addition,oxides contained in glass can also achieve the translucent and moist effects. Of course, there are other method which can reduce the transparency of glass and make the inner material present the effect of natural texture. Visual perception made by different material proportioning methods also varies. The creator should be clear about the role of each raw material in the glass manufacturing process so as to make the most ideallight transmission effect of glass in accordance with proportion.

The designer or artists create a large number ofglass artworks blooming with warmmoistness and plainness through skilled mastery of the glass material, which forms a contrast in style with crystal and clear glass creation .

Soft Glass. Lightness is intuitive visual perception brought by transparency of glass material. In particular, when glass is used as decorative curtain wall of buildings or artistic sculptures, such kind of feeling is most obvious. In architectural design, the emergence of glass has replaced the traditional 
construction materials such as stone and brick etc. In 1851, the Crystal Palace used in industrial exposition can be described as a marvelous spectacle in the history of architecture,. The remarkable building marks the important position of glass in architectural design. Thereafter, glass has extended from the traditional window surface to the whole wall. The design pattern by taking glass as wall, iron and steel as frameworkhas become a typical symbol of modern architecture. As it were, the appearance of glass decorative curtain wall has changed design ideas of modern architectural designer. The outstanding western architectural designers have created a number of stunning architectural works of art through clever and skillful use of the glass material. Glass material reduces the weight of the building and set up a bridge between the indoor and outdoor environment so that the closed building can take a breath. In addition, the visual space of viewers is extended and it provides a relaxed and warm environment for the rapid pace of life in city. It shows that architectural designers' understanding of glass is not only limited to the simple structural function of wall. They are trying to maximize the charm of glass material and exploring to enrich architectural design language from an aesthetic point of view. Numerous living examples of domestic and foreign architectures have indicates that glass material is able to meet people's emotional dependence on architecture. Especially for different forms of decorative art glass, clever and skillful decoration technique is able to create an environment with interaction between people and architecture and such environment may arouse people's sense of pleasure or be able to soothe certain uneasiness in inner heart of people.

The light and soft texture displays the graceful and elegant quality of glass incisively and vividly. And such feeling gives us sense of affability and mildness. Therefore, many glass creators prefer to utilize the texture of glass material to satisfy audience's pursuit of beauty.

\section{Summary}

Thus it can be seen that, materials for glass decoration art should pay attention to capturing the character of material itself and its texture features, which is important aspects to reflect the soul of glass art.

\section{References}

[1] Wang Min, The vierics. Shanghai Scientific and Technological Education Publishing House., Shanghai, 2006,pp 247.

[2] Wang Chengyu, Art Glass and Decorative Glass., Chemical Industry Press,Beijing, 2009,pp53.

[3] Penny Sparke, Design in Italy, Abbeville Press., Vitreous Publication, Colton, 1989.

[4] Dan Klein, Glass A Contempoary Art, Rizzoli., New York,1989 .

[5] Information on http://bj.house.sina.com.cn. 